\title{
Perceptual weights for loudness reflect central spectral processing.
}

\section{Joshi, Suyash Narendra; Jesteadt, Walt}

\section{Published in:}

Acoustical Society of America. Journal

Publication date:

2011

\section{Document Version}

Publisher's PDF, also known as Version of record

Link back to DTU Orbit

Citation (APA):

Joshi, S. N., \& Jesteadt, W. (2011). Perceptual weights for loudness reflect central spectral processing. Acoustical Society of America. Journal, 132(3).

\section{General rights}

Copyright and moral rights for the publications made accessible in the public portal are retained by the authors and/or other copyright owners and it is a condition of accessing publications that users recognise and abide by the legal requirements associated with these rights.

- Users may download and print one copy of any publication from the public portal for the purpose of private study or research.

- You may not further distribute the material or use it for any profit-making activity or commercial gain

- You may freely distribute the URL identifying the publication in the public portal

If you believe that this document breaches copyright please contact us providing details, and we will remove access to the work immediately and investigate your claim 


\title{
Session 3aPP
}

\section{Psychological and Physiological Acoustics: Perception and Models}

\author{
G. Christopher Stecker, Chair \\ Speech and Hearing Sciences, University of Washington, Seattle, WA 98105
}

\section{Contributed Papers}

$8: 30$

3aPP1. Infants' ability to separate superimposed vowels. Lynne Werner, Bonnie Lau, and Ashley Flad (Speech \& Hearing Sciences, University of Washington, 1417 North East 42nd Street, Seattle, WA 98105-6246, lawerner@u.washington.edu)

Three- and seven-month-old infants were tested using an observer-based procedure in three tasks to assess sound source segregation and selective attention. The stimuli were tokens of the vowels $/ \mathrm{a} /$ and $/ \mathrm{i} /$, spoken by two male talkers, $519 \mathrm{~ms}$ in duration, presented at $70 \mathrm{~dB}$ SPL. Success was defined as achieving $80 \%$ correct in fewer than 40 test trials. In the first task, infants heard one vowel spoken by one talker repeated at $1319 \mathrm{~ms}$ intervals. They learned to respond when the talker changed on one repetition of the vowel. In the second task, the tokens of the two talkers producing the same vowel were superimposed. Infants heard combined tokens repeatedly and learned to respond when the vowel produced by one talker changed. In the third task, either talker could produce the changed vowel. Infants learned to respond when one talker, but not the other, produced the changed vowel. Nearly all infants succeeded in the first two tasks. Nearly all 7-month-olds, but few 3-month-olds succeeded at the third task. These results suggest that the ability to selectively attend to one of two easily discriminable voices matures after the ability to segregate those voices. [Work supported by R01DC00396 and P30DC04661.]

\section{$8: 45$}

3aPP2. Off-frequency masking effects on intensity discrimination. Harisadhan Patra (Audiology \& Speech Pathology, Bloomsburg University, 226 CEH, 400 E 2nd Street, Bloomsburg, PA 17815, hpatra@bloomu.edu), Scott Seeman (Department of Communication Sciences \& Disorders, Illinois State University, Normal, IL), Adam Burkland, Joseph Motzko, and Erin Lolley (Audiology \& Speech Pathology, Bloomsburg University, Bloomsburg, PA)

Intensity discrimination, where a listener detects an intensity increment in an equal duration sinusoid or pedestal, is often used as a measure of intensity resolution. Intensity discrimination may be considered as tone-in-tone masking, where the pedestal is the masker and the increment is the signal. Despite the similarity between intensity discrimination and tone-in-noise masking, research suggests that a high-pass noise outside the critical band centered on the signal frequency adversely affects listeners' intensity-discrimination thresholds. The present study examines the limits of off-frequency masking effects on intensity discrimination in five normal-hearing young adults. Detection thresholds for a 50-ms increment, added to a 50ms-long $1000-\mathrm{Hz}$ pedestal in phase, were obtained in quiet and notchednoise (NN) conditions. The pedestal and noise levels were $60 \mathrm{~dB}$ SPL. NN stimuli were generated by filtering telegraph noise. The low-frequency cutoffs of the NN-notches were $188,250,375,500$, and $750 \mathrm{~Hz}$ while the highfrequency cutoffs were 1500, 2000, 3000, 4000, and $6000 \mathrm{~Hz}$. The detection thresholds were poorer in NN conditions than in quiet, even when cutoff frequencies were more than one octave away from the signal frequency. Effects of off-frequency maskers on the psychometric functions are discussed. [Supported by BU research and scholarship grant.]
9:00

3aPP3. Perceptual weights for loudness reflect central spectral processing. Suyash N. Joshi and Walt Jesteadt (Psychoacoustics Laboratory, Boys Town National Research Hospital, 555 N 30th St., Omaha, NE 68131, Suyash.Joshi@boystown.org)

Weighting patterns for loudness obtained using the reverse correlation method are thought to reveal the relative contributions of different frequency regions to total loudness, the equivalent of specific loudness. Current models of loudness assume that specific loudness is determined by peripheral processes such as compression and masking. Here we test this hypothesis using 20-tone harmonic complexes $(200 \mathrm{~Hz}$ f0, 200 to $4000 \mathrm{~Hz}, 250 \mathrm{~ms}$, $65 \mathrm{~dB} /$ Component) added in opposite phase relationships (Schroeder positive and negative). Due to the varying degree of envelope modulations, these time-reversed harmonic complexes have been shown to produce different outputs at the basilar membrane and different amounts of forward and simultaneous masking. The perceptual weights for loudness did not differ for these two complexes. To determine whether the level rove introduced to obtain weights had changed the fundamental differences in the stimuli, a similar level rove $( \pm 8 \mathrm{~dB})$ was introduced on each component of Schroeder positive and negative forward maskers. The Schroder negative maskers continued to be more effective. These results suggest that perceptual weights for loudness are not completely determined by peripheral processes and reflect a central frequency weighting template. [Work supported by NIH R01 DC011806 and P30 DC004662.]

\section{9:15}

3aPP4. Temporal weighting of interaural time and level differences carried by broadband noises. G. C. Stecker (Speech and Hearing Sciences, University of Washington, 1417 NE 42nd St, Seattle, WA 98105, cstecker@ uw.edu)

Localization of real sounds involves integrating acoustic spatial cues as they evolve over time. This study measured binaural sensitivity over time, in the form of temporal weighting functions (TWFs) for trains of of noise bursts. Each stimulus comprised sixteen 1-ms bursts of white noise, presented at an interval (ICI) of 2 or $5 \mathrm{~ms}$. In separate conditions, noise samples were either repeated ("frozen") or newly generated ("fresh") across bursts. On each of many trials, listeners indicated the apparent lateral position of a stimulus along a horizontal scale displayed on a touch-sensitive device. Lateral positions varied across trials as interaural time (ITD) and level (ILD) differences ranged +/-500 $\mu$ s ITD or +/-5 dB ILD. Interaural differences of individual bursts in each train received additional random variation (ranging $+/-100 \mu \mathrm{s}$ and $+/-2 \mathrm{~dB}$ ) to allow calculation of TWFs by multiple linear regression of normalized responses onto per-burst ITD and ILD values. Consistent with past studies, TWFs for "frozen" noise-burst trains demonstrated large ICI-dependent weights on the initial burst ("onset dominance"), elevated weights near offset, and lower weights for interior bursts. Flatter TWFs, smaller onset/offset weights, and greater interior weights were measured for "fresh" vs "frozen" noise burst trains. [Supported by R01 DC011548.] 